\title{
CFD study on the effect of Archimedes number and heating rate on the thermal stratification of a ventilated office
}

\author{
Mehrdad Rabani $^{1} \quad$ Habtamu B. Madessa ${ }^{1} \quad$ Natasa Nord $^{2}$ \\ ${ }^{1}$ Department of Civil Engineering and Energy Technology, OsloMet - Oslo Metropolitan University, Norway, \\ \{Mehrdad.Rabani, Habtamu-Bayera.Madessa\} @oslomet.no \\ ${ }^{2}$ Department of Energy and Process Engineering, Norwegian University of Science and Technology, Norway, \\ natasa.nordentnu. no
}

\begin{abstract}
This paper dealt with simulating a typical occupied office equipped with displacement ventilation using CFD method. The STAR-CCM+ commercial software was employed for performing the simulations in order to analyze the trend of the indoor air temperature profile in the office occupied space. Understanding this trend is a key parameter to ensure that the occupants are comfortable and thereby further conclusions on energy efficiency could be extracted. The simulations were carried out for incompressible, turbulent, and constant property air flow in the steady state condition. The results showed that increasing the number of occupants, while Archimedes number was constant, would increase the throw length of the incoming cold jet leading to an overall lower temperature profile for the case with five occupants.
\end{abstract}

Keywords: Ventilation, CFD, Archimedes number, Temperature stratification

\section{Introduction}

Ventilation system effectiveness plays a prominent role in the improvement of indoor air quality (IAQ) of buildings (Sundell, 1988). In modern societies, people spend a lot of their time (on average more than 90\%) in indoor environments (Bruinen de Bruin, 2008), therefore the need for good IAQ is considered as imperative. In addition, ventilation stands for $20 \%$ to $40 \%$ of total building energy use in modern countries (Pérez-Lombardm, 2008). This can undeniably justify the importance of special care for mechanical ventilation system, especially in countries characterized with cold climate such as Norway, where using natural ventilation is seldom possible.

There are two common methods implemented in ventilation systems for replacing the used air with fresh air: mixing and displacement ventilation. The mixing ventilation has the capability to remove considerable amounts of excess heat without risk of draft and the air temperature is almost well mixed (Hestnes and Eik-Nes, 2017).

In displacement ventilation, the system delivers fresh air directly to the occupied zone leading to an efficient removal of pollutants and excess heat. However, this results in a thermal stratification of air in the occupant zone that in turn may cause discomfort if the gradient exceeds a certain level (Nielsen, 2000). Therefore, understanding the air temperature profiles and the influencing parameters are crucial to assess the comfort conditions in displacement ventilation systems.

Modelling of temperature and velocity flow fields is challenging in ventilation systems. It requires a knowledge of both 1) impact of each room component on the room physics, and 2) the interaction of all of these effects simultaneously. Nevertheless, Computational Fluid Dynamics (CFD) is a well-established method and has proven its competence in simulating the ventilation system performance (Nielsen, 2009; MenchacaBrandan et al, 2017).

As a common practice in most of CFD studies, a set of dimensionless parameters are defined to better investigate the effect of a parameter on the flow field and thermal stratifications. Using the dimensionless parameters will make the results functional for all the parameter combinations as long as they do not influence the physics of the flow in the room, e.g. they do not change the turbulence regime to laminar and vice versa etc. (Sonin, 2001).

The dimensionless parameters that are often considered for studying the flow field characteristics, e.g. vertical temperature gradient and velocity distribution are the Archimedes, Reynolds, and Prandtl numbers. Previous numerical and experimental studies demonstrated that the effect of Reynolds and Prandtl numbers are trivial on the temperature variation especially in displacement ventilation (Nielsen, 1988). However, the Archimedes number has shown a great potential to affect the thermal stratification considerably (Nielsen, 1988; Corgnati et al, 2009). The Archimedes number is defined as Eq. (1). 


$$
A r=\frac{g \beta \Delta T h}{u^{2}}
$$

where the $g$ is the gravity acceleration, $\beta$ is the air volume expansion coefficient, $u$ is the supply velocity, $\Delta T$ is the temperature difference between outlet and inlet, and $h$ is the height where the supply terminal is placed (Nielsen, 1988). In order to better predict the thermal stratification (Menchaca-Brandan, 2012) considered the following model:

$$
A r=\frac{g \beta \Delta T h^{3}}{u^{2} A_{s}}
$$

where $A_{s}$ is the area of supply terminal.

This paper examined the effect of the Archimedes number on the air temperature stratification and velocity distribution in a typical occupied office equipped with displacement ventilation using CFD. The most important contribution of this study was to indicate how CFD could be used to investigate the combined effect of different heating rate due to occupancy and Archimedes numbers (for high buoyancy and high supply momentum) on the air temperature stratification and velocity distribution. The aim was to test the capability of the simulation software in capturing the phenomena happen in extreme condition.

\section{Methodology and case study}

\subsection{Geometry specifications}

In order to study the effect of different parameters on the temperature stratification, the office building model proposed by (Menchaca-Brandan, 2012) was used. The building is an open plan office. Due to symmetry, only one repeating part of the open plan office was considered for simulations in order to reduce the computational cost. The office was ventilated using the displacement method.

Figure 1 shows the geometry and dimensions of the model used for CFD simulations. The room has two inlets and one outlet. The outlet area was fixed $(2 \mathrm{~m}$ width and $0.2 \mathrm{~m}$ height) and its upper edge was placed $0.1 \mathrm{~m}$ from the ceiling. The inlets were placed $1 \mathrm{~m}$ from the floor with constant total area of $0.06 \mathrm{~m}^{2}$.

The heating source was a seated occupant modelled as a cylinder with round-top shape having $1.13 \mathrm{~m}$ height and $0.62 \mathrm{~m}$ diameter and located centrally in the office (Menchaca-Brandan and Glicksman, 2011). Three and five (Figure 1) occupants were considered for simulations. In both cases, the distance of the first occupant was $2 \mathrm{~m}$ from the inlet wall and the distance between each one is $2 \mathrm{~m}$ and $4 \mathrm{~m}$ in the case of five and three occupants, respectively.

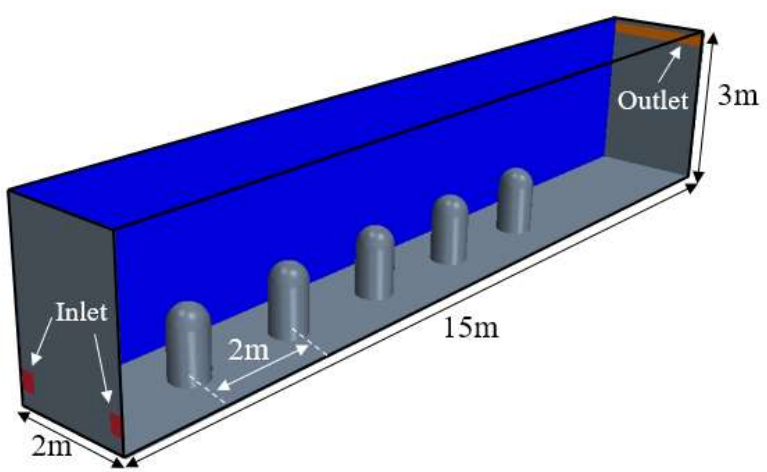

Figure 1. Dimensions and geometry of case study

\subsection{CFD model}

The commercial code STAR-CCM+ (Version 12.04.010) was used for the numerical solution of the RANS (Reynolds-Averaged Navier-Stokes) and energy equations. The software has In-Situ Adaptive integral Tabulations and a number of other methods to speed up computation. The whole CFD workflow including CAD, meshing, solving, optimization, and postprocessing can be automated in one macro. The software solves the RANS equations in their integral form, by means of Finite Volume (FV) method. The simulation cases were run in steady state condition. The segregated solver was chosen that uses the SIMPLE pressure-velocity coupling algorithm where the mass conservation constraint on the velocity field is fulfilled by solving a pressure-correction equation. It should be noted that the segregated solver has its roots in constantdensity flows (STAR-CCM+ User Guide, 2017).

In order to check if the steady state condition was reached, the mass flow rate difference between outlet and inlet as well as the outlet temperature were monitored during the simulations, which the first one should be approximately zero and the latter should be nearly equal to the outlet temperature calculated from energy conservation equation.

\subsubsection{Boundary conditions}

Figure 2. indicates the boundary conditions of the CFD model implemented in STAR-CCM+. At inlets, a constant air velocity boundary condition was defined. The inlet temperature was $19^{\circ} \mathrm{C}$. The outlet was modelled as pressure outlet with zero gauge pressure. Due to symmetrical conditions, the side wall surfaces of the office were modelled with symmetry boundary condition as shown in Figure 2. Ceiling was considered as the surface with constant heat flux of $8 \mathrm{~W} / \mathrm{m}^{2}$ (around $25 \%$ of total heat flux in a typical office) representing heat gain due to lighting (Menchaca-Brandan, 2012). Other walls and surfaces were considered adiabatic. This study focused on the ventilation during working hours. The heat gain due to occupant was modelled as a heating source emitting a fixed amount of $120 \mathrm{~W}$, which 
is associated with a seated person with metabolic rate 1 Met (Fanger, 1972).

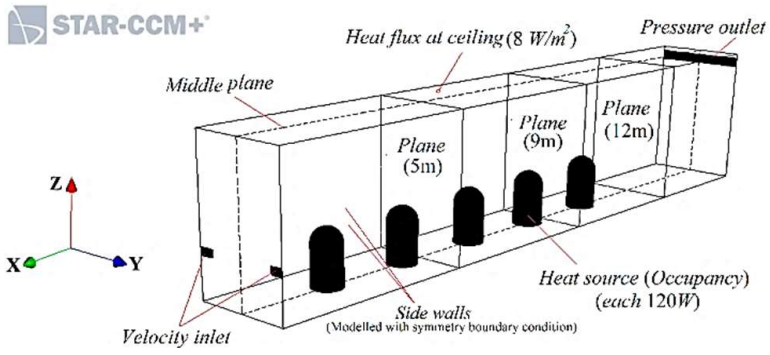

Figure 2. Boundary conditions and measured planes of CFD models in STAR-CCM+

\subsubsection{Simulation specification}

The flow regime was considered fully turbulent. Therefore, the Shear Stress Transport k-omega (SST k$\omega)$ turbulence model was adopted for simulations due to its decent performance regarding supply jet behavior, prediction of buoyancy turbulence interaction, and temperature stratification in ventilated buildings (Gilani et al, 2016). The computational domain discretization was obtained by means of a polyhedral-shaped mesh (Figure 3a). It is numerically more stable, less diffusive, and more accurate than an equivalent tetrahedral mesh (STAR-CCM+ User Guide, 2017). In order to perform a grid independence study, four meshes with 2033458 , 1203867,526027 , and 119742 cells were investigated. The mesh with 1203866 cells was chosen, giving lesser computational time, because the maximum discrepancy between the temperature value for this mesh and the largest mesh with 2033458 cells was less than $2.5 \%$, as shown in Figure 3b. An inflation layer around the surface was also used to capture high gradients generated within a small region near the walls and surfaces accurately with a $y+\leq 5$. Figure $3 c$ illustrates the frequency of $y+$ near the heating source surfaces. Maximum frequency of $\mathrm{y}+$ occurs at $\mathrm{y}+\sim 0.023$, which is much less than 5 indicating the mesh properly resolved the viscosity-affected region near the wall and recaptured the heat transfer from surfaces to the flow in the human thermal plume. The radiation was modelled using surface to surface (S2S) model behaving the air as transparent to radiation. The emissivity of all walls was defined to be 1 owing to typical materials used in an office have usually an emissivity approximately 1 (Menchaca-Brandan, 2012).

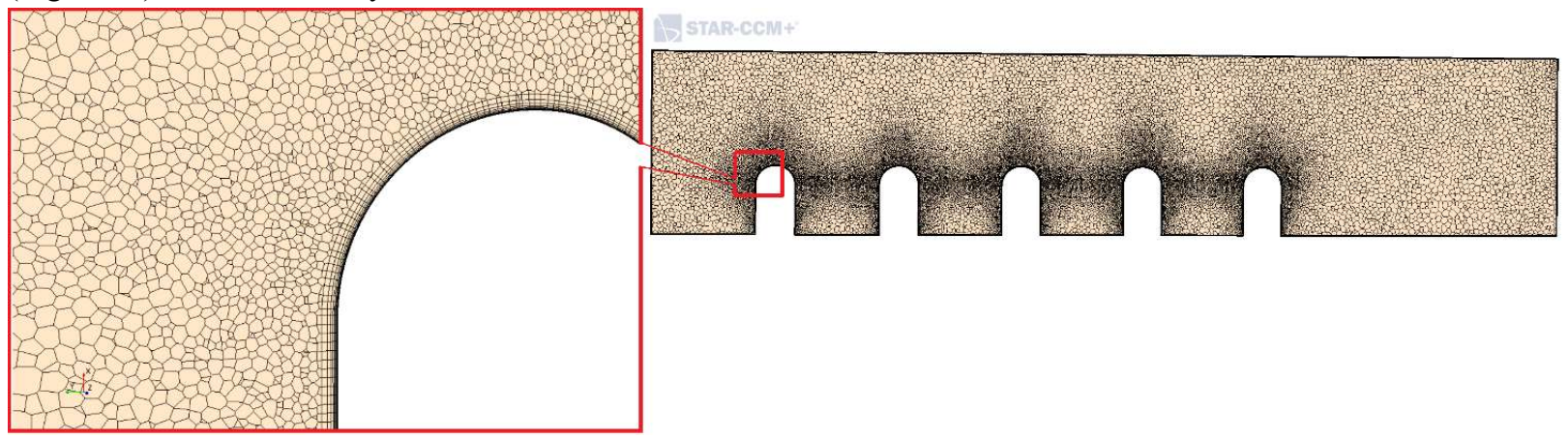

Figure 3a. Mesh generation used in this study with inflation layer around surface

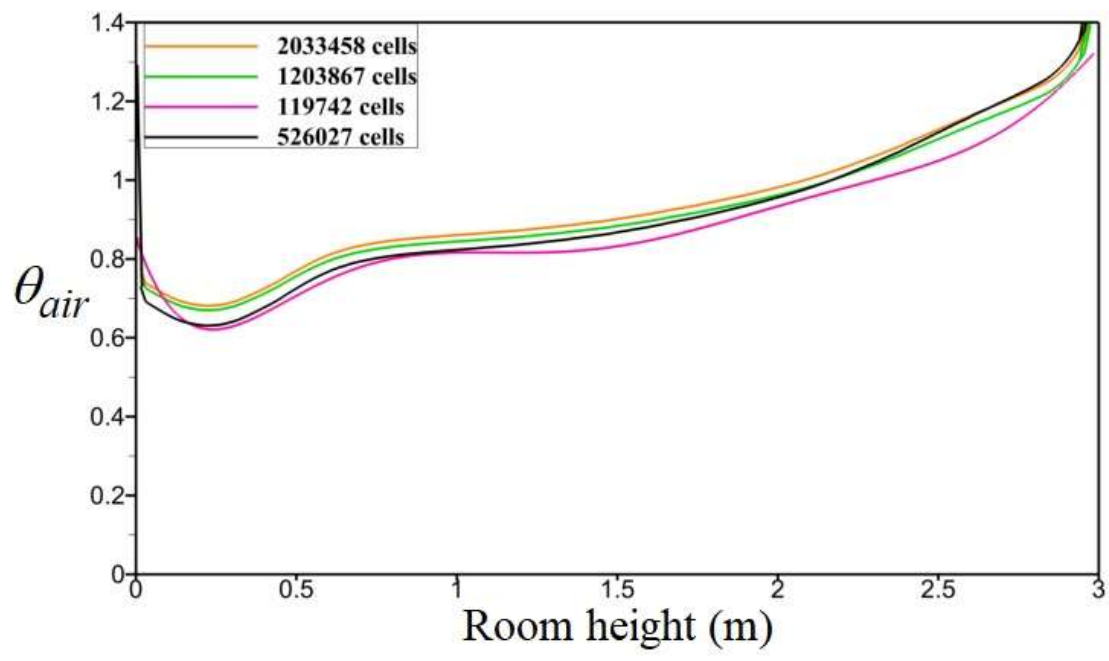

Figure 3b. Vertical temperature profile for different mesh cell numbers 


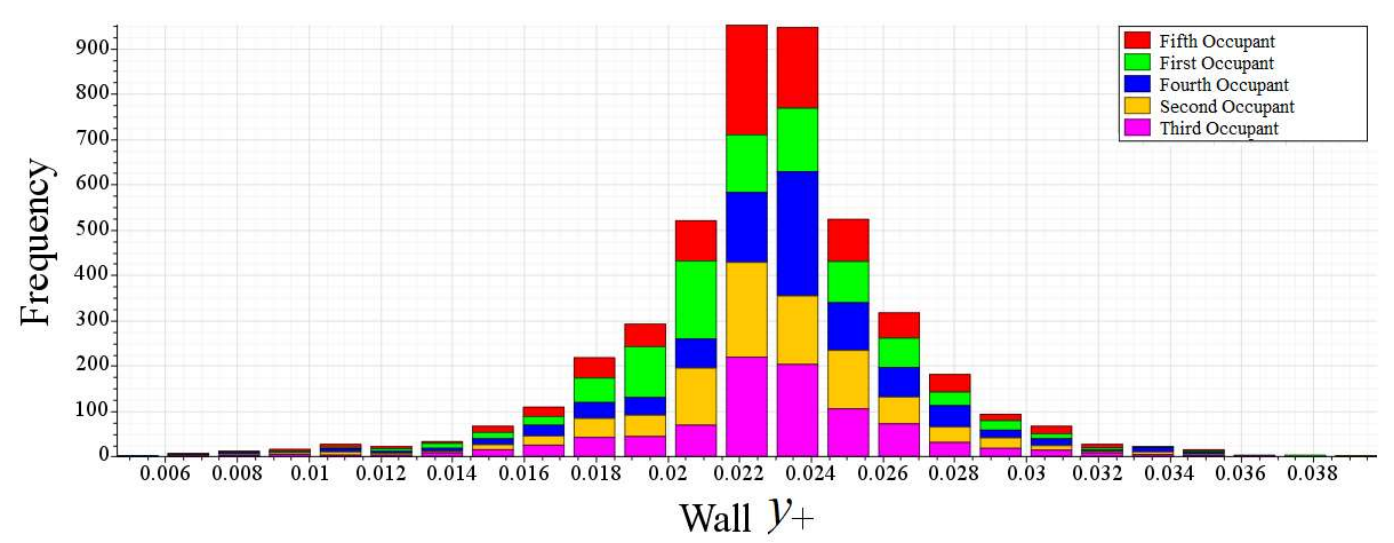

Figure 3c. Wall $y+$ frequency on the thermal heating walls

\subsection{Validation and verification}

The method was validated by previous experimental and numerical studies. The first simulation was performed in order to replicate the experimental results of an air flow in a rectangular room in the presence of radiation (Figure 4a) (Olson et al. 1990).

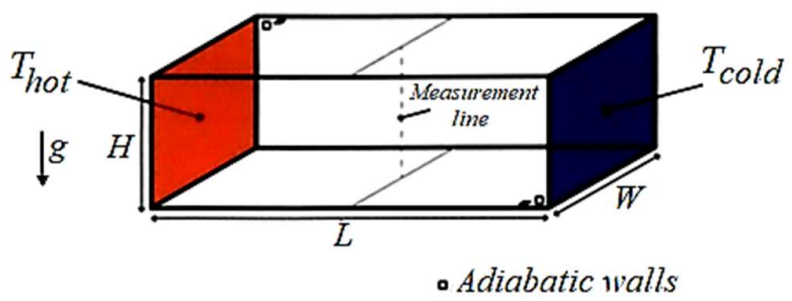

Figure 4a. Configuration of rectangular enclosure. The rectangle in dotted lines corresponds to the location where measurements were performed (Olson et al, 1990).

The experimental setup used for validation purpose has been shown in Table 1. The Rayleigh number, which is a dimensionless number indicating whether the natural convection boundary layer is laminar or turbulent, was defined as follows:

$$
R a_{L}=\frac{g \beta\left(T_{\text {hot }}-T_{\text {cold }}\right) L^{3}}{v \alpha}
$$

Where $L, v, \alpha$, and $\beta$ are the length of the room, kinematic viscosity, thermal diffusivity, and thermal expansion coefficient of the air, respectively. According to the calculated Rayleigh number in Table 1, the flow was considered turbulent.

Table 1. Experimental setup used by (Olson et al, 1990)

\begin{tabular}{|l|c|}
\hline Room Length $(L)$ & $7.9(\mathrm{~m})$ \\
\hline Room Width $(W)$ & $3.9(\mathrm{~m})$ \\
\hline Room Height $(H)$ & $2.5(\mathrm{~m})$ \\
\hline $\mathrm{T}_{\text {hot }}($ Temperature of cold wall) & $36.6\left({ }^{\circ} \mathrm{C}\right)$ \\
\hline $\mathrm{T}_{\text {cold }}($ Temperature of hot wall) & $19.9\left({ }^{\circ} \mathrm{C}\right)$ \\
\hline Rayleigh number $\left(R a_{L}\right)$ & $6.98 \times 10^{11}$ \\
\hline
\end{tabular}

Figure $4 \mathrm{~b}$ shows the comparison of present numerical simulation with previous experimental and numerical works. As it can be noted, the present numerical method fairly replicates the experimental results, even better than previous numerical study especially for the points near the ceiling. This shows that STAR-CCM+ can be used to study displacement ventilation in an office building, where both the radiative and convective heat transfers are present.

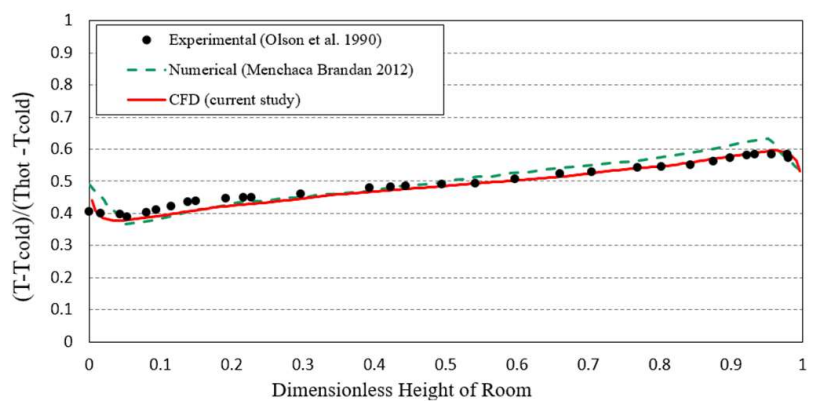

Figure 4b. Comparison of dimensionless temperature variation on the vertical line

\subsection{Archimedes number analysis}

Four cases were considered for simulations in terms of combination effects of two different Archimedes number and two different heating rates. Two sets of three and five number of occupants were considered. Furthermore, two Archimedes numbers of 60 and 0.5 were selected. In order to better interpret these combined effects, the Archimedes number was rewritten using energy conservation equation in the space as follows:

$$
A r=\frac{g \beta \dot{Q} h^{3}}{\rho c_{p} u^{3} A_{s}^{2}}
$$

where $\dot{Q}$ is the total heat gains in the room. The geometric properties in Eq. 4 ( $h$ and $A_{S}$ ) were considered constant. Therefore, with regard to the selected Archimedes number, the inlet velocity in each simulation case was chosen so that the supply volumetric air flow rate was always kept higher than the 
minimum standard air amount for Norwegian nonresidential buildings (TEK17).

Temperature profiles were measured at three different measuring planes, located at $5 \mathrm{~m}, 9 \mathrm{~m}$, and 10 $\mathrm{m}$ from the inlet wall respectively (see Figure 2). Temperature gradients were compared using the following dimensionless form:

$$
\theta_{\text {air }}=\frac{T-T_{\text {in }}}{T_{\text {out }}-T_{\text {in }}}
$$

\section{Results and discussion}

Figure 5 indicates the effect of different Archimedes number and different number of heating rates on the dimensionless temperature variation. As can be seen from Figure 5, at high Archimedes number (cases (c) and (d)), there almost existed a two-structured zone with lower stratified temperature profile in the occupancy zone and upper destratified temperature profile formed due to convective effect of human thermal plume. However, at the low Archimedes number (cases (a) and (b)), the higher velocity of supply jet mixes the cold supply air with thermal plume of heating rate causing the uniform temperature zone to be distorted and the temperature near the ceiling to increase. Furthermore, a higher heating rate (more occupants) would result in a lower air temperature value in the space when the Archimedes number is kept constant (compare the cases (c) and (d)).

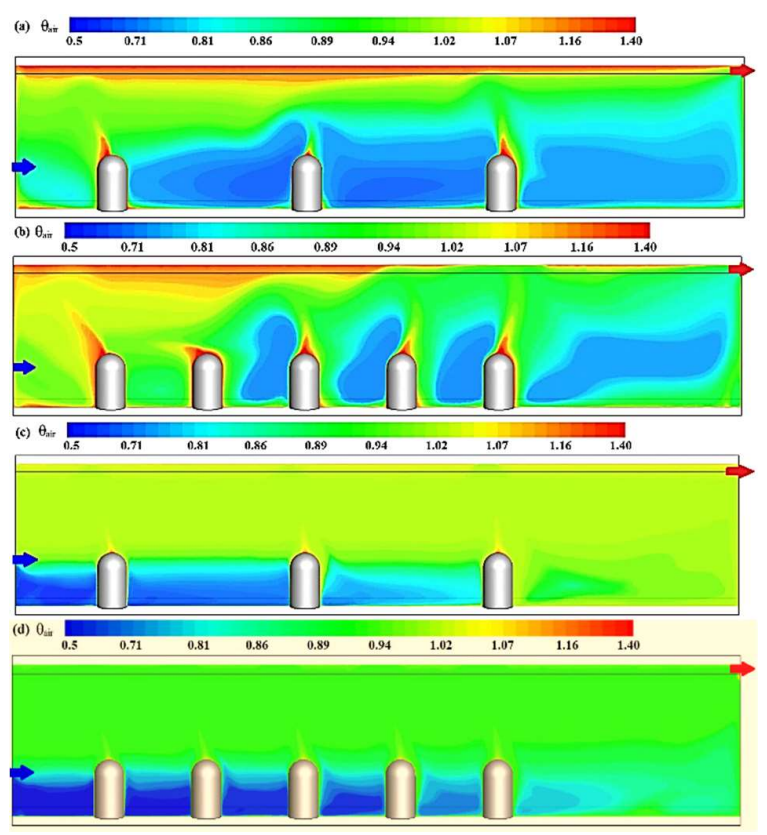

Figure 5. Temperature distribution contour for cases: (a) $A r=0.5, N=3$, (b) $A r=0.5, N=5$, (c) $A r=60, N=3$, and (d) $A r=60, N=5$. Results were given along the middle plane. Inlet and outlet have been specified with blue and red arrows, respectively.
Figure 6 illustrates the combined effect of heating rate and the Archimedes number on the velocity distribution in the office space. At the low Archimedes number, the inlet supply air moving across the space reached the outlet wall and rises to higher heights and then return to the inlet until it is entrained by the supply air flow. This phenomenon is less pronounced at the high Archimedes number, since the lower velocity of supply jet returning from the outlet wall cannot overcome the human thermal plume rise. It is worth noticing that the simulation tool could properly capture the recirculating zones created due to interaction of the human plume and the cold supply jet.
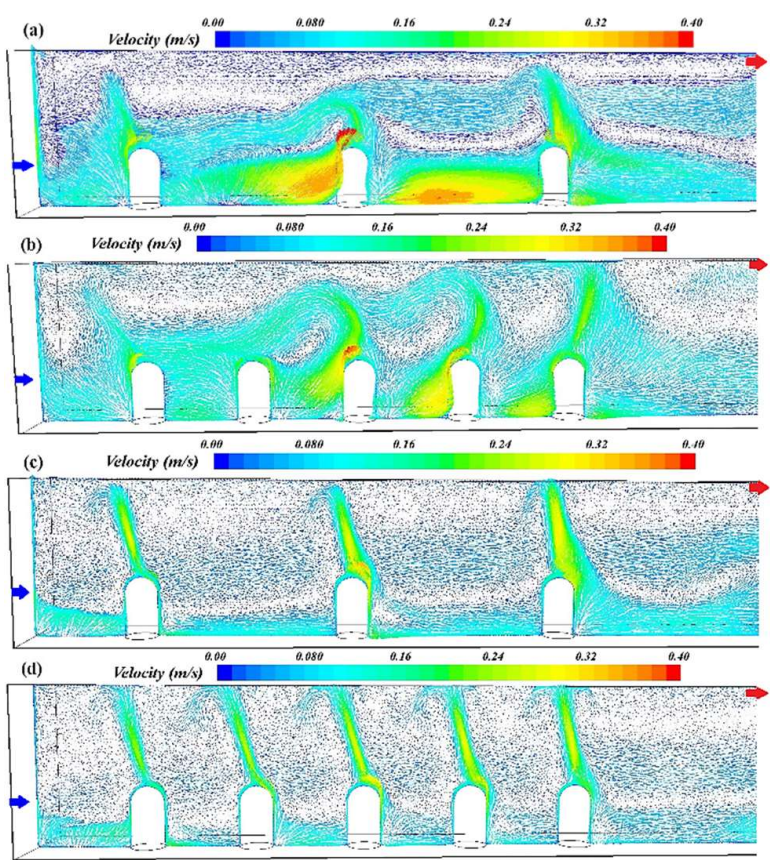

Figure 6. Air velocity distribution and vectors along the middle plane: (a) $A r=0.5, N=3$, (b) $A r=0.5, N=5$, (c) $A r=60, N=3$, and (d) $A r=60, N=5$. Inlet and outlet have been specified with blue and red arrows, respectively.

Figure 7 indicates the development of temperature profile for different Archimedes numbers and heating rates. Due to high velocity of the supply jet, the low Archimedes number shows a larger overall vertical temperature variation than the high Archimedes number. Increasing the number of occupants, while Archimedes number was constant, would increase the throw length of the incoming cold jet leading to an overall lower temperature profile for the cases with five occupants. In addition, the air temperature near the floor was higher than its neighbor region due to radiation from the ceiling.

Figure 8 indicates the vertical temperature variation in three measured planes in one specific case. Temperature near the floor was lower at $x=5 \mathrm{~m}$ compared to the other cases due to the effect of the cold supply jet. Likewise, the temperature near the ceiling was higher at $\mathrm{x}=5 \mathrm{~m}$ owing to the fact that the cold 
supply jet after reaching the outlet wall returned to the inlet and was mixed with the thermal plume near the ceiling and was accumulated near the inlet wall until it was entrained by the supply jet. The temperature variation, in general, in the occupancy zone was less at $\mathrm{x}=9 \mathrm{~m}$ and $12 \mathrm{~m}$ compared to $\mathrm{x}=5 \mathrm{~m}$, because it was less influenced by the incoming cold jet at these planes.

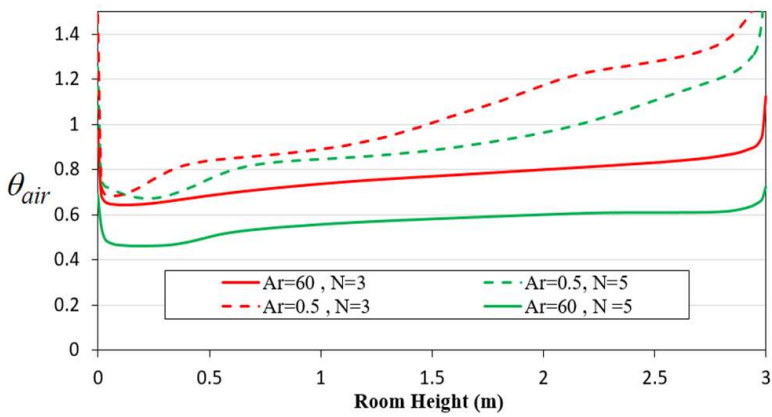

Figure 7. Dimensionless temperature profile at the plane $\mathrm{x}=5 \mathrm{~m}$

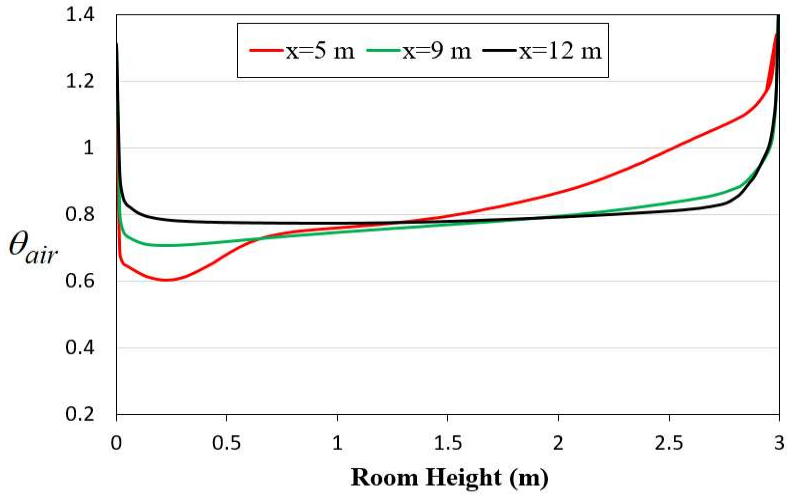

Figure 8. Dimensionless temperature profile at the planes $\mathrm{x}=5 \mathrm{~m}, 9 \mathrm{~m}$, and $12 \mathrm{~m}$ for $A r=0.5, N=5$

The effect of cold supply jet for different Archimedes numbers and heating rates is illustrated in Figure 9. At the low Archimedes number (cases (a) and (b)), the high momentum of the cold jet results in longer throw length and larger vertical temperature variation. The throw length of the cold jet in cases (a) and (b) was longer due to higher inlet velocity in these cases. However, at the high Archimedes number (cases (c) and (d)), the incoming jet fallen and reached the floor near the inlet due to strong buoyancy force of the warm air in the proximity. Consequently, a stratified layer was formed in the occupancy zone, while a convective recirculating zone was formed due to buoyancy effect of human thermal plumes in the upper part.

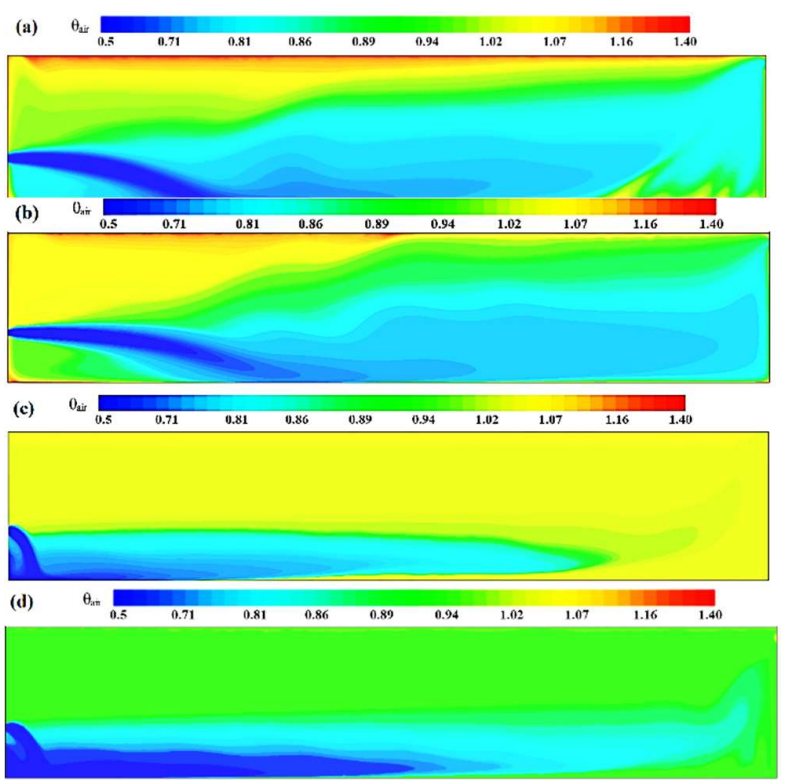

Figure 9. Temperature distribution contour for cases: (a) $A r=0.5, N=3$, (b) $A r=0.5, N=5$, (c) $A r=60, N=3$, and (d) $A r=60, N=5$. Results were given along the symmetry plane.

\section{Conclusion}

In this study, four cases of combinations of the Archimedes number and the heating rates were investigated by means of CFD method. Simulations were performed using STAR CCM + software. The results indicated that the high Archimedes number resulted in the dominant phenomenon of the buoyancy of convective flow induced by the human thermal plume. Therefore, two structured areas were formed in the space: a lower zone with stratified temperature profile due to interaction of the incoming cold jet and the thermal plume and an upper recirculating zone with the destratified temperature profile due to convective effect of human thermal plume. For the low Archimedes number, high momentum of the incoming jet disrupts the flow field resulting in mixing of the cold jet with convective flow of the thermal plume in the space. Increasing the number of the heating sources decreased the overall vertical temperature. Furthermore, the results indicated that the software properly captured the convective recirculating regions created by thermal plume as well as the vertical temperature gradient in both buoyant and high momentum flows.

It is worth mentioning that the present results in this study showed the capability of STAR CCM+ for numerical study of buildings ventilated by displacement ventilation. As further study, STAR CCM+ will be used to investigate the effect of the high and low Archimedes numbers in mixing ventilation systems. 


\section{References}

Y. Bruinen de Bruin, K. Koistinen, S. Kephalopoulos, O. Geiss, S. Tirendi and D. Kotzias (2008): Characterisation of urban inhalation exposures to benzene, formalde- hyde and acetaldehyde in the European Union: comparison of measured and modelled exposure data. Environmental Science and Pollution Research, 15(5):417-430.

S.P. Corgnati, M. Perino, G.V. Fracastoro and P.V. Nielsen (2009): Experimental and numerical analysis of air and radiant cooling systems in offices. Building and Environment, 44:801-06.

P.O. Fanger (1972): Thermal Comfort, McGraw-Hill, New York, USA.

S. Gilani, H. Montazeri and B. Blocken (2016): CFD simulation of stratified indoor environment in displacement ventilation: Validation and sensitivity analysis. Building and Environment, 95:299-313.

A.G. Hestnes and N.L. Eik-Nes (2017): Zero emission buildings. Bergen. Fagbokforlaget, 107-121.

M.A. Menchaca-Brandan and L.R. Glicksman (2011): How to replicate computationally a human plume with a simple geometry, and how not to, in: Proceedings of RoomVent, Trondheim, Norway.

M.A. Menchaca-Brandan (2012): Study of Airflow and Thermal Stratification in Naturally Ventilated Rooms. $P h D$ thesis, Massachusetts Institute of Technology.

M.A. Menchaca-Brandan, F.A. Dominguez Espinosa and L. R. Glicksman (2017): The influence of radiation heat transfer on the prediction of air flows in rooms under natural ventilation. Energy and Buildings, 138:530-38.

P.V. Nielsen (1988): Displacement Ventilation in a Room with Low-Level Diffusers. Aalborg: Department of Building Technology and Structural Engineering, Aalborg University. Indoor Environmental Technology, R8836(10).

P.V. Nielsen (2000): Velocity distribution in a room ventilated by displacement ventilation and wall-mounted air terminal devices. Energy and Buildings, 31:179-87.

P.V. Nielsen (2009): CFD in Ventilation Design: a new REHVA Guide Book. Aalborg: Department of Civil Engineering, Aalborg University.

D.A. Olson, L.R. Glicksman and H.M. Ferm (1990): Steadystate natural convection in empty and partitioned enclosures at high Rayleigh numbers. Journal of Heat Transfer (Transactions of the ASME (American Society of Mechanical Engineers), Series (C), 112(3):109-111.

L. Pérez-Lombard, J. Ortiz and C. Pout (2008): A review on buildings energy consumption information. Energy and Buildings, 40:394-398.

A.A. Sonin (2001): The Physical Basis of Dimensional Analysis. Technical Report, Massachusetts Institute of Technology.

J. Sundell (2004): On the history of indoor air quality and health. Indoor Air, 14:51-58.

STAR-CCM+ User Guide (2017), Version 12.04.010, CDadapco.

Veiledning om tekniske krav til byggverk (2017). Byggteknisk forskrift- TEK17. 